\title{
Articulo Original / Original Article The study of Yangyinyiqi mixture anti bleomycin-induced pulmonary fibrosis on rats by intervening matrix metalloproteinase-9 and tissue inhibitors of matrix metalloproteinases-1
}

[El estudio de la mezcla Yangyinyiqi en fibrosis pulmonar inducida por anti-bleomicina en ratas por intervención en la matriz metaloproteinasa-9 e inhibidores de tejido de matriz metalopreoteinasa-1]

\author{
Hong Wang ${ }^{1,2}$, Chen-Yu Zhao ${ }^{3,4}$, Yong Zhu ${ }^{1}$, Ji-Pu Zhou ${ }^{1}$, Wen Yin ${ }^{3}$, Zhi-Yong Li ${ }^{3}$, Xue-Qing Yang ${ }^{5}$ \& Xin-Ping Qiu ${ }^{6}$ \\ ${ }^{1}$ Respiratory Department, Beijing Hospital of Traditional Chinese Medicine, Beijing, China \\ ${ }^{2}$ Respiratory Department, Shunyi Hospital, Beijing Hospital of Traditional Chinese Medicine, Beijing, China \\ ${ }^{3}$ Respiratory Department, Minzu University of China, Institute of Chinese Minority Traditional Medicine, Beijing, China \\ ${ }^{4}$ Respiratory Department, Dandong School of Traditional Chinese Medicine, Dandong, China \\ ${ }^{5}$ Cardiovascular Department, Shunyi Hospital, Beijing Hospital of Traditional Chinese Medicine, Beijing, China \\ ${ }^{6}$ Research Department, Shunyi Hospital, Beijing Hospital of Traditional Chinese Medicine, Beijing, China
}

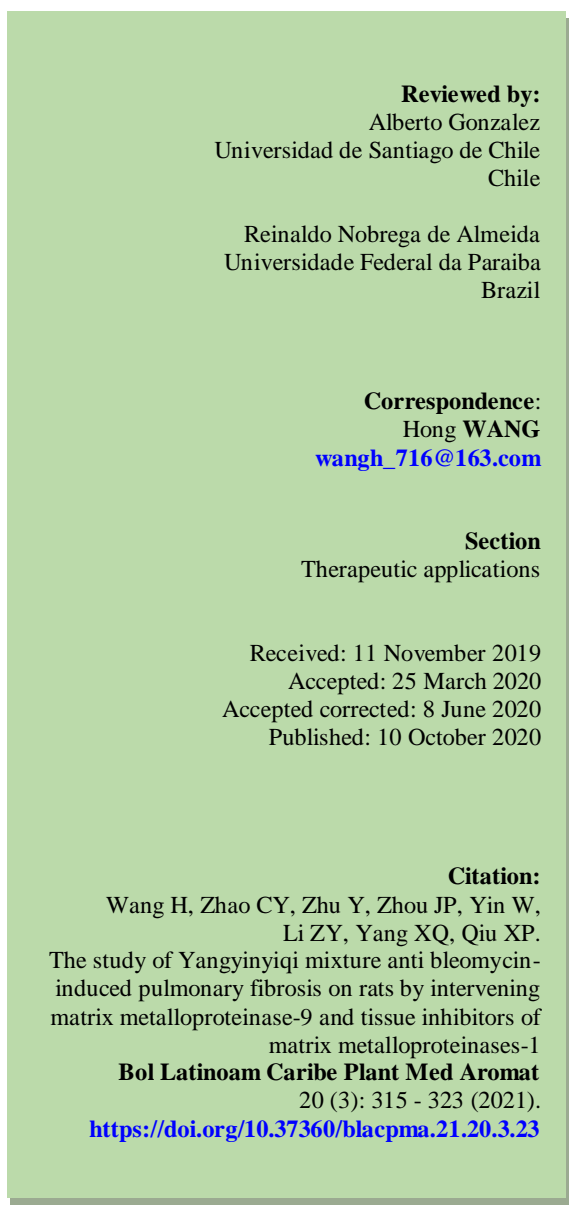

Abstract: To investigate effects of Yangyinyiqi Mixture on pulmonary fibrosis caused by bleomycin. SD rats were divided randomly into: model group (distilled water, $1 \mathrm{~mL} \cdot 0.1 \mathrm{~kg}-1$ ), dexamethasone acetate group (dexamethasone acetate, the dosage was reduced gradually), low-dose group (Yangyinyiqi Mixture, $11 \mathrm{~g} \cdot \mathrm{kg}-1$ ), moderate-dose group (Yangyinyiqi Mixture, $22 \mathrm{~g} \cdot \mathrm{kg}-1$ ), high-dose group (Yangyinyiqi Mixture, $44 \mathrm{~g} \cdot \mathrm{kg}-1$ ) and control group (distilled water, $1 \mathrm{~mL} \cdot 0.1 \mathrm{~kg}-1$ ). Yangyinyiqi Mixture and dexamethasone acetate were intragastrically administrated. Lung tissue was collected for histopathological examination. Compared with control group, collagen markedly increased and HYP content significantly increased on 7 th day in model group $(p<0.01)$. On 28th day, collagen was diffusely deposited, alveolar was destroyed, and HYP content significantly increased $(p<0.01)$. Compared with model group, bleomycin-induced suffering injury caused MMP-9 expression levels to rapidly increase (7 and 14 days, $p<0.01$ ). TIMP- 1 markedly increased ( 7 and 14 days, $p<0.01)$ and stayed at a high level to 28th day. Yangyinyiqi Mixture exerted an effect against pulmonary fibrosis, which could involved prevention of collagen deposition through inhibiting MMP-9 and TIMP-1 expression.

Keywords: Yangyinyiqi Mixture; Pulmonary fibrosis; Hydroxyproline; Matrix metalloproteinases; Tissue inhibitors of matrix metalloproteinases.

Resumen: El trabajo investiga los efectos de la mezcla Yangyinyiqi sobre la fibrosis pulmonary causada por bleomicina. Ratas SD se dividieron aleatoriamente en: grupo modelo (agua destilada, $1 \mathrm{~mL} \cdot 0.1 \mathrm{~kg}-1$ ), grupo acetate de dexametasona (acetate de dexametasona, la dosis se redujo gradualmente), grupo de dosis baja (mezcla Yangyinyiqi, $11 \mathrm{~g} \cdot \mathrm{kg}-1$ ), grupo de dosis moderada (mezcla Yangyinyiqi, $22 \mathrm{~g} \cdot \mathrm{kg}-1$ ), grupo de dosis alta (mezcla Yangyinyiqi, $44 \mathrm{~g} \cdot \mathrm{kg}-1$ ) y grupo control (agua destilada, $1 \mathrm{Ml} \cdot 0.1 \mathrm{~kg}-1$ ). La mezcla de Yangyinyiqi y el acetate de dexametasona se administraron por vía intragastrica. Se recolectó tejido pulmonary para examen histopatológico. En comparación con el grupo control, el colágeno aumentó notablemente y el contenido de HYP aumentó significativamente el séptimo día en el grupo modelo $(p<0.01)$. El día 28 , el colágeno se depositó difusamente, se produjo destrucción alveolar y el contenido de HYP aumento significativamente $(p<0.01)$. En comparación con el grupo modelo, la lesion inducida por bleomicina causó que los niveles de expression de MMP-9 aumentaron rapidamente (7 y 14 días, $p<0.01$ ). TIMP-1 aumentó notablemente (7 y 14 días, $p<0.01)$ y se mantuvo en un nivel alto hasta el día 28. La mezcla Yangyinyiqi ejerció un efecto contra la fibrosis pulmonary, lo que podría implicar la prevención del deposito de colágenio mediante la inhibición de la expression de MMP-9 y TIMP-1.

Palabras clave: Mezcla Yangyinyiqi; Fibrosis pulmonar; Hidroxiprolina; Matriz-metalproteinasa; Inhibidores tisulares de matriz-metaloproteinasas. 


\section{INTRODUCTION}

Pulmonary fibrosis (PF) early inflammatory reaction, which is alveolar damage in essence, is caused by the late interstitial collagen deposition of the extracellular matrix in the alveoli and lung; and eventually, PF occurs (Sibinska et al., 2017; Atzenni et al., 2018). Epidemiological studies have shown that the incidence of PF has continuously shown an increasing trend (He \& Xiong, 2018; Li \& Liu, 2019). Statistics has shown that the average survival time after diagnosis of PF is less than 5 years and the mortality rate is high, which poses a serious threat to people's health (Chioma \& Drake, 2017). Current approved treatment methods of PF, such as pirfenidone and nintedanib, have been shown to reduce the decline of forced vital capacity and slow the progression of disease in PF patients (Bonella et al., 2015). Dexamethasone acetate is also a first-line drug for the treatment of pulmonary diseases, including $\mathrm{PF}(\mathrm{Xu}$ et al., 2011). However, the most effective treatment at present is still lung transplantation (Fujimoto et al., 2015).

$\mathrm{PF}$ belongs to the category of "lung shrinking" in traditional Chinese medicine (Gao et al., 2016). In traditional Chinese medicine (TCM), the pathogenesis of PF involves the deficiency in Qi and Yin, and the presence of blood stasis (Li \& Kan, 2017). The therapeutic goal of PF is to replenish qi and nourish yin (a TCM therapeutic method), promote blood circulation and detoxification, thereby nourishing and ventilating the lung and reducing the symptoms. The Yangyin Yiqi mixture was prepared by the Beijing Hospital of Traditional Chinese Medicine Affiliated to Capital University of Medicine Sciences, which was developed by Dr. ZhenYing Wen. This mixture is mainly composed of Huangqi (Astragalus mongholicus), Dangshen (Codonopsis pilosula), Beishashen (Radix glehniae), Huangjing (Rhizome polygonati), Xuanshen (Radix scrophulariae), and Zicao (Radix lithospermi). A large number of data has shown that the Yangyin Yiqi mixture has a satisfactory curative effect on early diabetic nephropathy, oral lichen planus, childhood asthma, and SARS (Wang et al., 2003; Liu et al., 2006; Qian, 2007; Guan et al., 2011; Gong \& Wang, 2004. Our preliminary clinical study revealed that it can improve the PF Qi and Yin deficiency syndrome in patients and animals with lung function and delay disease development to improve the quality of life (Wang et al., 2016; Meng et al., 2019a; Meng et al., 2019b).

Matrix metalloproteinases 9 (MMP-9) and its specific inhibitor, called matrix tissue inhibitors of matrix metalloproteinases 1 (TIMP-1) are the key proteins associated with the accumulation and degradation of extracellular matrix (Roderfeld et al., 2007). MMP-9 is not produced in normal lung tissues. Under stimulation, however, MMP-9 can be released by bronchial epithelial cells, Clara, lung tissue cells, alveolar type II cells and fiber cells. In this study, we aimed to investigate the effects of Yangyin Yiqi Mixture intervention on the pulmonary expressions of MMP-9 and TIMP-1 in rats with bleomycin (BLM)-induced PF.

\section{MATERIALS AND METHODS}

\section{Animals}

Six-week-old male Sprague-Dawley SPF grade rats $(200 \pm 20 \mathrm{~g})$ were obtained from Charles River Laboratories (provided by Vital River Laboratory Animal Technology Ltd., China; SCKK2012-0001) and maintained in a pathogen-free environment with a 12-h light-dark cycle. All animal experiments were approved by the Beijing Administration Office of Laboratory Animals, and were performed according to the Prevention of Cruelty to Animals Act 1986, NIH Guidelines for the Care and Use of Laboratory Animals, and local laws.

\section{Drugs and Reagents}

Yangyin Yiqi mixture (Beijing TCM Hospital Affiliated to Capital Medical University, China, 20130130); dexamethasone acetate tablets (Li Sheng Pharmaceutical Co. Ltd., Tianjin, China, 1209028); bleomycin injection (Nippon Kayaku Co. Ltd., Japan, 420202); Masson trichrome staining solution (Loogene Bio Technology Co. Ltd., Beijing, China); Hydroxyproline Assay Kit (Nanjing Jiancheng Bioengineering Institute, Nanjing, China, 20130412); MMP-9 goat polyclonal antibody and TIMP-1 rabbit polyclonal antibody (Santa Cruz Biotechnology, USA); $\beta$-actin mouse monoclonal antibody, HRPlabeled goat-anti-rabbit and HRP-labeled rabbit-antigoat (Zhongshan Goldenbridge Biotechnology Co. Ltd., China).

\section{Instruments}

TE16721 Inverted Fluorescence Microscope (Olympus, Japan); FlexStation 3 Microplate Detection System (Molecular Devices, USA); Vertical Electrophoresis System (Baygene Biotech Co. Ltd., China); Powerpachv Power, 170-3940 Fast Semi-Dry Blotter, S2003-RC-230 Vertical Reciprocating Shaker and Metal Heater (Bio-Rad, USA). 


\section{Experimental grouping and animals model} establishment

The rats were randomly assigned into six groups: model group, dexamethasone acetate group, low-dose of Yangyin Yiqi Mixture group (low-dose group, 11 $\mathrm{g} \cdot \mathrm{kg}-1)$, moderate-dose of Yangyin Yiqi Mixture group (moderate-dose, $22 \mathrm{~g} \cdot \mathrm{kg}-1$ ), high-dose of Yangyin Yiqi Mixture group (high-dose, $44 \mathrm{~g} \cdot \mathrm{kg}-1$ ), and control group. Rats were housed under constant temperature $\left(22^{\circ} \mathrm{C}\right)$ and humidity $(60 \%)$, and had free access to food and water ad libitum.

Just before reperfusion, the rats were intraperitoneally anesthetized with $10 \%$ chloral hydrate solution $(0.3 \mathrm{~g} / \mathrm{kg}$, converted from general human clinical dosage), fixed on the anatomical plate, and the trachea was exposed layer by layer. BLM (1.5 mg/kg) was intratracheally and rapidly sprayed into rats as close as possible to the bifurcation of the trachea. After the injection, the needle was pulled out immediately. The anatomical plate was raised and slowly rotated for approximately two minutes, in order to allow the BLM solution to be distributed evenly in the two lungs. Rats in the normal control group received an injection of saline $(1.5 \mathrm{mg} / \mathrm{kg})$ at the same time.

\section{Drug Administration}

One day after the model establishment, the positive drug group was given dexamethasone acetate. Initial dosage was $1 \mathrm{mg} \cdot \mathrm{kg}-1$ for three days, and the dosage was change to $0.8 \mathrm{mg} \cdot \mathrm{kg}-1$ for the succeeding three days. After every two days, the dosage was gradually reduced, as follows: $0.6,0.4,0.2$, and $0.1 \mathrm{mg} \cdot \mathrm{kg}-1$. On the 14th day, administration was stopped. The dosage of the Yangyin Yiqi Mixture in the low-dose group, moderate-dose and high-dose group was 11 $\mathrm{g} \cdot \mathrm{kg}-1,22 \mathrm{~g} \cdot \mathrm{kg}-1$, and $44 \mathrm{~g} \cdot \mathrm{kg}-1$, respectively, according to the calculation of crude drug. Furthermore, the control group and model group were orally given distilled water at $1 \mathrm{~mL} \cdot 0.1 \mathrm{~kg}-1$.

\section{Masson Staining Method}

For detection experiments, $1 / 3$ of the rats in each group were selected after 7, 14 and 28 days, respectively. Rats were intraperitoneally injected with $10 \%$ chloral hydrate solution for anesthesia, and fixed on the anatomic plate in the supine position. Then, chests were opened, the right main bronchi were ligated, and the right lungs were removed and stored in a freezer at $-80^{\circ} \mathrm{C}$. The flat-head needle went through from the apical into the right ventricle, and the hemostatic clamp was fixed on the tissues.
The left atrial appendage was cut open, rapidly perfused with 100-200 ml of PBS, and slowly infused with $4 \%$ formaldehyde solution until the left atrial appendage outflowed colorless liquid. The left lungs were removed and fixed in $4 \%$ formaldehyde solution. Then, the tissues went through paraffin embedding, slicing and Masson staining.

\section{Quantitation of Hydroxyproline Content in Lungs}

The same portion (100mg) of the lung samples were used for HYP assessment. The content of HYP in lung tissue was determined by the alkaline hydrolysis method following the manufacturer's instructions.

\section{Western Blot}

Sample Preparation: Lung tissues were crushed in RIPA buffer $(50 \mathrm{~mm}$ of Tris $\mathrm{pH} 7.0,150 \mathrm{mM}$ of $\mathrm{NaCl}$, and $1 \%$ Triton $\mathrm{X}-100)$. Then, the homogenates were mutated at $4{ }^{\circ} \mathrm{C}$ and centrifuged at $12,000 \mathrm{~g}$ for 30 minutes. The supernatant (the total protein sample) was collected. Protein quantitation was carried out according to the instructions of the BCA protein assay kit. Samples were packaged according to the amount of the test.

Electrophoresis: (1) proteins were separated by $10 \%$ SDS-PAGE. The molecular ladder was Prestained Protein Ladder (Abcam, Cambridge, UK). (2) Preparation of the membrane: The PVDF membrane was cut according to the size of the gel, and incubated in methanol for approximately one minute on a rocker at room temperature. The methanol was removed and the membrane was equilibrated in transfer buffer until ready to use. (3) Gel-membrane sandwich assembly: The transfer cassette was opened in a shallow tray. A well-soaked sponge pad was placed on the black piece of the transfer cassette and soaked a $3 \mathrm{MM}$ paper on the sponge pad. The gel was placed and arranged well on the paper to remove all the air bubbles. The PVDF membrane was laid on the top of gel and all air bubbles were removed. The soaked sheet of $3 \mathrm{MM}$ paper was placed over the PVDF membrane, and bubbles were removed. This, this was covered using the second well-soaked pad, and the sandwich was closed with a white piece of the cassette. The sandwich was mounted in the transfer tank, and the black sides were placed near the black side of the device. The buffer tank was filled with the transfer buffer. (4).

Electrophoresis: The electrodes were attached, and the power supply was set to $100 \mathrm{~V}$ (constant voltage) for one hour at $4{ }^{\circ} \mathrm{C}$. 
Immunodetection: (1) Membrane blocking and washing: The transfer apparatus was disconnected, the transfer cassette was removed, and the $3 \mathrm{MM}$ paper was peeled from membrane. Then, the membrane was removed and placed in a small container, $10 \mathrm{ml}$ of TBS buffer was added and washed for short time, blocked with $5 \%$ non-fat dried milk in Tris-buffered saline containing $0.1 \%$ TritonX-100 (TBST), rocked gently at room temperature for two hours, and incubated overnight at $4^{\circ} \mathrm{C}$ with the primary antibodies: MMP-9 goat polyclonal antibody, TIMP-1 rabbit polyclonal antibody, and $\beta$-actin mouse monoclonal antibody (1:200 dilution in fresh 5\% skimmed milk powder sealing solution). Then, the blocking buffer was poured off and rinsed briefly with TBST buffer three times for 15 minutes per time. The TBST buffer was poured off and the secondary antibodies were added at appropriate dilutions in 5\% nonfat dried milk. Then, the membranes were incubated with the secondary antibodies: HRP-labeled goat-anti-rabbit antibody and HRP-labeled rabbit-anti-goat antibody (1:1500 in Fresh 5\% skimmed milk powder sealing solution). (2) Detection: The TBST buffer was poured off from membrane and developing reagent was added, rocked the PVDF gently, and the reaction was monitored. When the bands could be clearly seen, the reaction was stopped by washing the membrane with distilled water for 30 minutes with three changes. Subsequently, the membrane was exposed to the X-ray film for $20-30$ seconds. Western blot results were quantified by the analysis of X-ray films using the Image $\mathbf{J}$ software.

\section{Statistical analysis}

All quantitative data were expressed as mean \pm standard error of the mean (SEM). Statistical evaluation was carried out with SAS for Windows 8.1. One-way Analysis of Variance (ANOVA) was used to discriminate differences between different groups. The level of significance was set to $p<0.05$.

\section{RESULTS \\ Effect of the Yangyin Yiqi Mixture on lung collagen deposition in PF rats}

Rats in the control group had normal lung structure. However, there was a small amount of collagen between the pulmonary alveolus. Compared with the control group, on the 7th day, collagen in lung tissues of model group rats markedly increased. On the 28th day, the collagen was diffusely deposited, and the alveolar structure was destroyed and gradually extended to the interstitial lung. Compared with the model group, the deposited collagen in lung tissues was alleviated in the positive drug group, but there was a collapse in the alveolus. Compared with the model group, the extent of PF in the moderate-dose and high-dose groups was less severe, especially in the high-dose group. The deposition of the collagen was significantly improved and the alveolar structure tends to stretch and complete. Collagen deposition condition in rats in the low-dose group slightly alleviated (Figure No. 1).

\section{Effect of the Yangyin Yiqi Mixture on HYP content in PF rats}

On the 7th day, HYP content in lung tissues of rats in the model group was significantly increased compared with the control group $(p<0.01)$. On the 28th day, HYP content in lung tissues of rats in the model group remained at an elevated level $(p<0.01)$. Compared with model group, HYP content was remarkably reduced in the moderate- and high-dose groups $(p<0.01)$ in a dose-dependent manner. The efficacy of the high dose Yangyin Yiqi Mixture was almost equivalent with dexamethasone acetate group (Table No. 1)

\section{Effect of the Yangyin Yiqi Mixture on MMP-9 expression in PF rats}

MMP-9 expression was low in normal lung tissues. In the suffering injury caused by BLM, MMP-9 expression level elevated rapidly ( 7 and $14, p<0.01$ ) and remained at a high level up to the 28th day (28 days, $p<0.05)$. Furthermore, MMP-9 expression was inhibited in the high dose group (7 and 14, $p<0.01$; compared with the model group, respectively). MMP-9 expression in dexamethasone acetate group was similar to model group ( $p>0.05$, Figure No. 2$)$

\section{Effect of the Yangyin Yiqi Mixture on the expression of TIMP-1 in PF rats}

TIMP-1 expression was low in normal lung tissues. Suffering injury was caused by BLM, and TIMP-1 expression in lung tissues were markedly increased (7 days, $p<0.01$ ), which stayed at a high level up to the 28 th day (14 and 28 days, $p<0.05)$. TIMP-1 expression was inhibited in the high-dose group of Yangyin Yiqi Mixture of ( 7 and 14 days, $p<0.01 \mathrm{~m}$ compared with model group respectively). TIMP-1 expression in the dexamethasone acetate group was close to the model group ( $p>0.05$, Figure No. 3 ). 


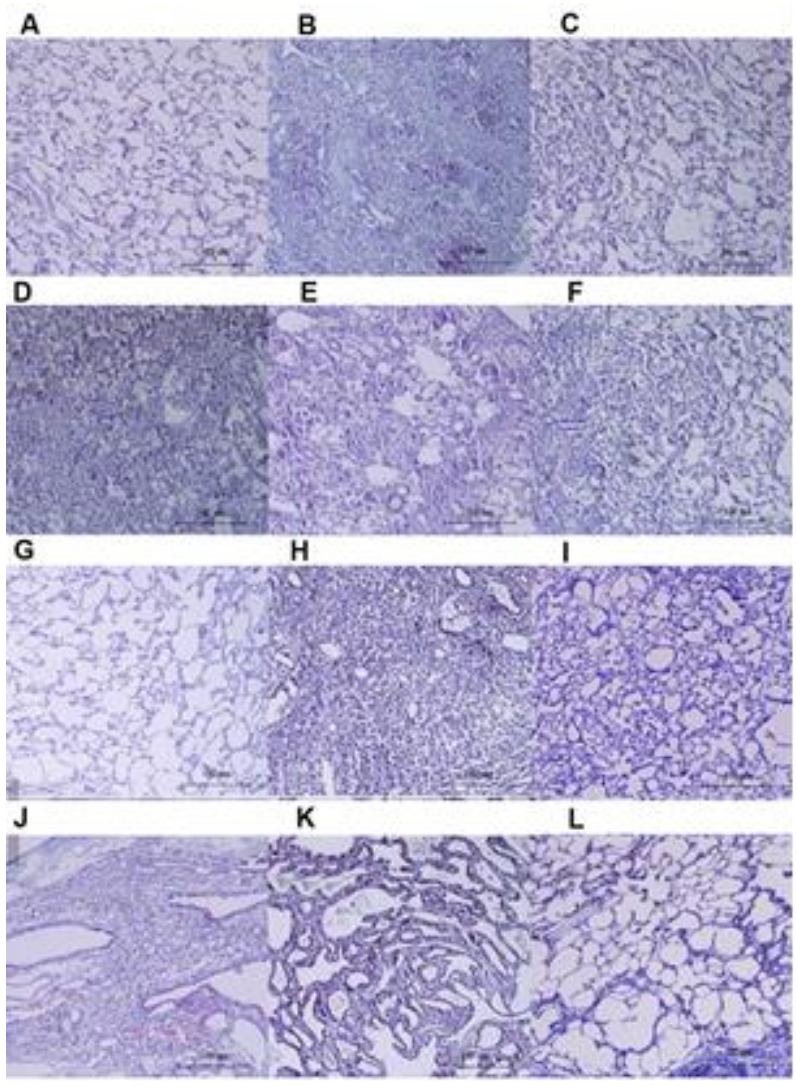

Figure No. 1

Masson staining $(\times 10)$ in all groups at different time points

(A) normal control group (7 d), (B) model group (7 d), (C) positive control group (7 d), (D) 11g/kg Yangyinyiqi mixture group (7 d), (E) 22g/kg Yangyinyiqi mixture group (7 d), (F) 44g/kg Yangyinyiqi mixture group (7 d), (G) normal control group (28 d), (H) model group (28 d), (I) positive control group (28 d), (G) 11g/kg Yangyinyiqi mixture group

(28 d), (K) 22g/kg Yangyinyiqi mixture group (28 d), (L) 44g/kg Yangyinyiqi mixture group (28 d)

Table $\mathbf{N}^{0} 1$

Effect of Yangyinyiqi Mixture on the content of hydroxyproline in rats of pulmonary fibrosis(mg/g) ( $\pm \mathrm{s})$

\begin{tabular}{|l|r|l|c|c|c|c|}
\hline \multicolumn{1}{|c|}{ Group } & N & \multicolumn{1}{|c|}{$\mathbf{7 d}(\mathbf{H Y P})$} & $\mathrm{N}$ & $\mathbf{1 4 d}(\mathbf{H Y P})$ & $\mathrm{N}$ & $\mathbf{2 8 d}(\mathbf{H Y P})$ \\
\hline Normal control & 10 & $541.60 \pm 165.86$ & 10 & $375.90 \pm 62.07$ & 10 & $388.90 \pm 91.46$ \\
\hline Model & 9 & $731.56 \pm 178.38 * *$ & 10 & $427.22 \pm 139.29$ & 10 & $631.10 \pm 92.44 * *$ \\
\hline Positive Drug & 12 & $609.08 \pm 184.53$ & 11 & $404.82 \pm 123.14$ & 10 & $340.40 \pm 86.13 \# \#$ \\
\hline $\begin{array}{l}\text { Low-dose of } \\
\text { Yangyinyiqi Mixture }\end{array}$ & 10 & $585.50 \pm 115.77$ & 10 & $398.40 \pm 109.06$ & 10 & $664.60 \pm 144.19$ \\
\hline $\begin{array}{l}\text { Moderate-dose of } \\
\text { Yangyinyiqi Mixture }\end{array}$ & 9 & $672.78 \pm 134.49$ & 10 & $411.00 \pm 75.44$ & 10 & $372.70 \pm 118.19 \# \#$ \\
\hline $\begin{array}{l}\text { High-dose of } \\
\text { Yangyinyiqi Mixture }\end{array}$ & 11 & $552.09 \pm 137.00 \# \#$ & 12 & $403.40 \pm 65.34$ & 9 & $426.80 \pm 81.54 \# \#$ \\
\hline
\end{tabular}

Note: HYP: hydroxyproline; $* * p<0.01$, vs normal control; \#\#p<0.01, vs model 


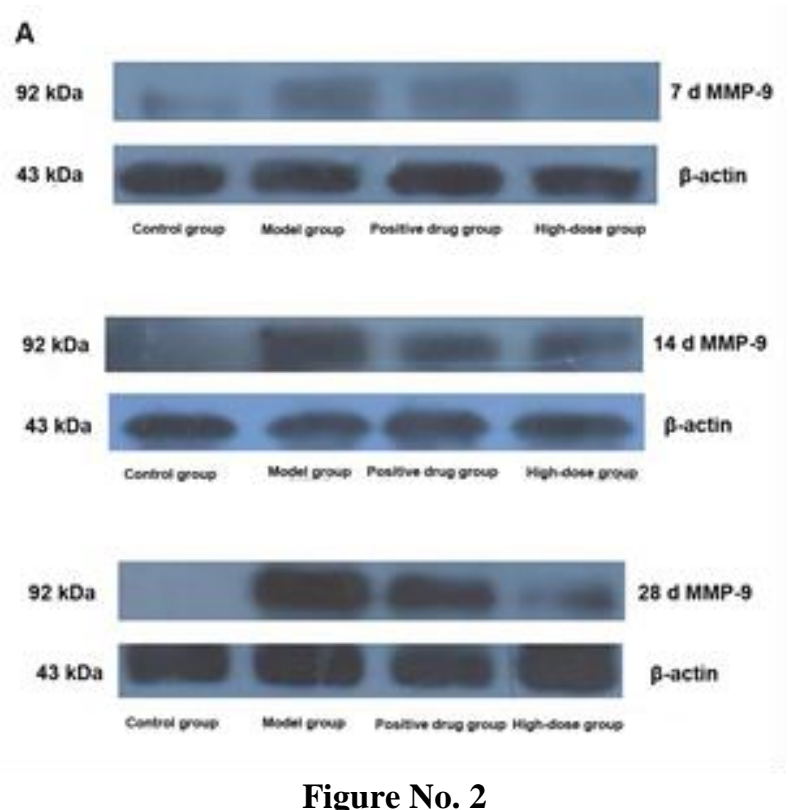

MMP-9 expression in different groups at day 7, 14, and 28

MMP-9 was in low expression in normal lung tissues.Suffering injury caused by bleomycin,the level of MMP-9 expression elevated quickly $(7 \mathrm{~d}, 14 \mathrm{~d} p<0.01)$ and stayed high level till 28 th day $(28 d p<0.05)$. High dose group of Yangyinyiqi Mixture inhibited expression of MMP-9 (7d, 14d $p<0.01$ compared with model group respectively). Expression of MMP-9 of dexamethasone acetate group approched to model group $(p>0.05)$. Results are expressed as Mean \pm S.D., $n=3$, ** $p<0.05$ compared with normal control group

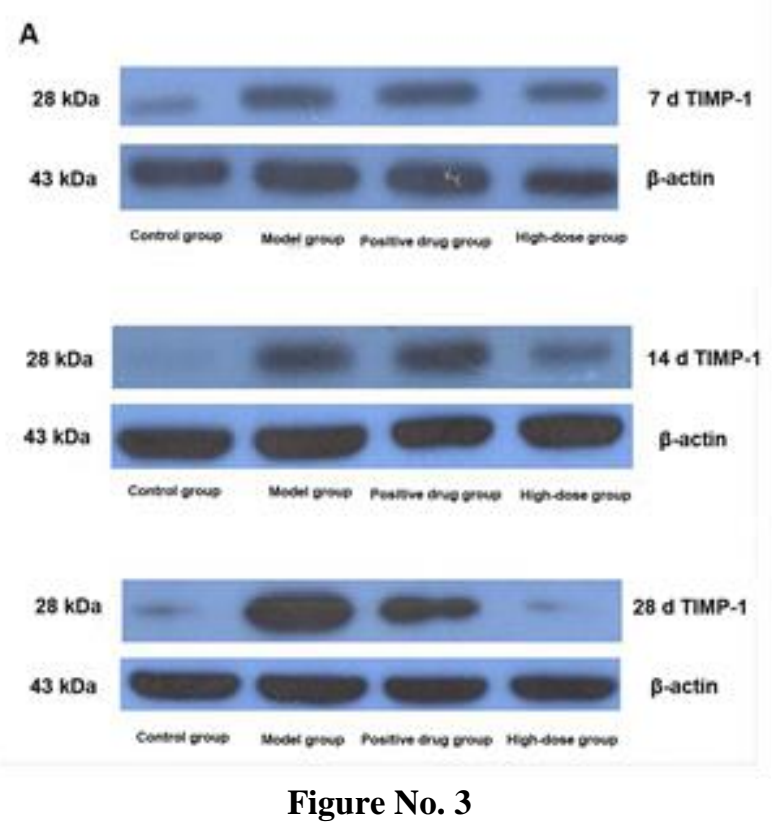

TIMP-1 expression in different groups at day 7, 14, and 28

TIMP-1 was in low expression in normal lung tissues. Suffering injury caused by bleomycin, TIMP-1 of the lung tissue expression were markedly increased $(7 \mathrm{~d} p<0.01)$ and stayed high level till 28 th day $(14 d, 28 d, p<0.05)$. High dose group of Yangyinyiqi Mixture inhibited expression of TIMP-1 (7d, 14d P<0.01 compared with model group respectively), Expression of TIMP-1 of dexamethasone acetate group approched to model group $(p>0.05)$. Results are expressed as Mean \pm S.D., $n=3$, **p $<0.05$ compared with normal control group; \#\# $p<0.05$, compared with model group 


\section{DISCUSSION}

The occurrence of PF interacts with a variety of factors or stimulus such as familial heredity, oxidative stress and inflammatory reaction, and persistent acute respiratory distress syndrome. Side effects of the long-term inhaled silica and BLM can induce PF (Andrade-Sousa et al., 2016). BLM, which is widely used in clinic for chemical adjuvant treatment, has significant cytotoxic and anti-cancer properties. During the process of its clinical use, BLM treated patients have a higher incidence of PF. Research has revealed that that BLM can cause DNA damage in the alveolar epithelium. This promotes chemokines to be released and activates white blood cells, which in turn induces PF (Yan et al., 2018). The use BLM preparation on a PF model is currently the most commonly used method in the international research of PF. The induction of PF has been proven to be related to genetic background and oxidative stress state (Zhang et al., 2017). MMPs and TIMPs in lung tissues are in a state of imbalance in patients with PF. Furthermore, excessive deposition of collagen protein in the lung parenchyma occurs (Gao et al., 2017). This experiment adopted the lower tracheal injection of $1.5 \mathrm{mg} / \mathrm{kg}$ of BLM to induce the PF model in rats (Wang et al., 2003; Liu et al., 2014). Results revealed that BLM can induce the formation of PF in rats. Lung tissue by Masson staining reveals blue, and the deposition of a large number of collagen fibers within the pulmonary interstitial can be observed.

In order to quantitatively evaluate the PF model and the efficacy of the prescription, the quantitative test of HYP in lung tissue of rats was performed. HYP is a characteristic of collagen ingredients, and collagens constitute the main components of the collagen fibers in the organizations. The PF process is the collagen deposition process. Hence, HYP content in lung tissues is widely used in the study of PF, and can effectively increase collagen fibers. A mold was made in this experiment. At each time point, the HYP content in rat lung tissues were higher than in the blank control group; and at seven and 28 days, this became more significant in the model group $(p<0.01)$. After BLM was given, collagen fiber content in lung tissues significantly increased. The Yangyin Yiqi mixture at low, medium and high doses can reduce HYP content in lung tissue of rats during this period. The description of the Yangyinyiqi Mixture can inhibit the production of collagen during the process of PF or accelerate its degradation and therapeutic effect on PF.

In patients with PF, MMP-9 is mainly produced by alveolar macrophages, neutrophils, and alveolar epithelial cells (Gao et al., 2017). Although observed in patients with PF and in lung tissues of experimental animals, MMP-9 greatly increases. However, it is difficult to infer from the results of MMP-9 knockout mice experiment what exact effects, promoting or inhibition, the increased MMP9 would exert on the formation and development of PF (Li \& Kan, 2017). No matter how after we observed in the experiments of BLM stimulation, MMP-9 has been in a state of high expression. A high dose of the Yangyin Yiqi mixture significantly prevented the rise of MMP-9. On the other hand, this significantly inhibited the PF promoter TIMP-1, which had an expression level close to the control group. Hence, it can be sure that inhibiting the expression of TIMP-1 is the main mechanisms of Yangyinyiqi Mixture to resist to PF. Moreover, our study showed that TIMP-1 had no intervention effect on dexamethasone acetate. In the late experimental (14 days) group, after the discontinuation of dexamethasone, MMP-9 expression has a certain degree of decline, deduce dexamethasone and not by regulating the expression of MMP-9 and TIMP-1 play the role of pulmonary fibrosis. Further measurements on the mRNA expressions of MMP-9 and TIMP-1 are needed to verify the regulation of Yangyinyiqi on these genes.

In conclusion, we reported that Yangyinyiqi Mixture prevented collagen deposition in rats with BLM-induced PF via the inhibition of MMP-9 and TIMP-1 expressions. These findings suggested the potential therapeutic property of Yangyinyiqi Mixture in ameliorating the progression of PF. Further investigations will be needed to explore the regulatory effects of Yangyinyiqi Mixture in other factors related to collagen deposition.

\section{REFERENCES}

Andrade-Sousa AS, Pereira PR, MacKenzie BA, Oliveira-Junior MC, Neto EA, Brandão-Rangel MAR, DamacenoRodrigues NR, Caldini EG, Velosa APP, Teodoro WR, Oliveira APL, Dolhnikoff M, Eickelberg O, Vieira RP. 2016. Aerobic exercise attenuated bleomycin-induced pulmonary fibrosis in Th2-dominant mice. PloS One 11: e0163420. https://doi.org/10.1371/journal.pone.0163420 
Atzeni F, Gerardi MC, Barilaro G, Masala IF, Benucci M, Sarzi-Puttini P. 2018. Interstitial lung disease in systemic autoimmune rheumatic diseases: A comprehensive review. Expert Rev Clin Immunol 14: 69 - 82. https://doi.org/10.1080/1744666X.2018.1411190

Bonella F, Stowasser S, Wollin L. 2015. Idiopathic pulmonary fibrosis: current treatment options and critical appraisal of nintedanib. Drug Des Devel Ther 9: 6407 - 6419. https://doi.org/10.2147/DDDT.S76648

Chioma OS, Drake WP. 2017. Role of microbial agents in pulmonary fibrosis.Yale J Biol Med 90: 219 - 227.

Fujimoto H, Kobayashi T, Azuma A. 2015. Idiopathic pulmonary fibrosis treatment and prognosis. Clin Med Insights Circ Respir Pulm Med 9: 179 - 185. https://doi.org/10.4137/CCRPM.S23321

Gao J, Wang TH, Han R, LI SM. 2017. Research progress of MMP-9 and TIMP-1 in pulmonary fibrosis. Shandong Med J 57: 104 - 106.

Gao Y, Yao LF, Zhao Y, Wei LM, Guo P, Yu M, Cao B, Li T, Chen H, Zou ZM. 2016. The chinese herbal medicine formula $\mathrm{mKG}$ suppresses pulmonary fibrosis of mice induced by bleomycin. Int J Mol Sci 17: 238. https://doi.org/10.3390/ijms17020238

Gong JS, Wang HT. 2004. Clinical observation of Yangyin Yiqi Mixture in treating patients with early diabetic nephropathy. Res Information Tradit Chin Med 6: 18 - 19.

Guan XB, Bai JP, Fu J, Wang LH, Li P, Sun Z. 2011. Effect of Traditional Chinese medicine yiqiyangyin on the level of related cytokines in serum of oral lichen planus patients. Beijing J Stomatol 19: 212 - 214.

He Q, Xiong J. 2018. Progress in research on pulmonary fibrosis mechanism. Chongqing Meicine 48: 3553 - 3557.

Li CD, Liu GT. 2019. New progress in diagnosis and treatment of pulmonary fibrosis. World Latest Medicine Information 18: $75-77$.

Li LC, Kan LD. 2017. Traditional Chinese medicine for pulmonary fibrosis therapy: Progress and future prospects. J Ethnopharmacol 198: 43 - 63. https://doi.org/10.1016/j.jep.2016.12.042

Liu X, Li P, Liang DY. 2006. Study of enhancing effects of Yangyin Yiqi Mixture on immuno-suppressed mice by hydrocortisone. Chin J Basic Med Trad Chin Med 12: 352 - 354.

Liu J, Liu YL, Wang WJ, Luo Y, Zhuang ZJ, Jiao QB, Chen JY, Bian DX, Ma XJ, Xun YH, Zhu MG, Shi JP. 2014. [Development and evaluation of a high-fat/high-fructose diet-induced nonalcoholic steatohepatitis mouse model]. Zhonghua Gan Zang Bing Za Zhi 22: 445 - 450.

https://doi.org/10.3760/cma.j.issn.1007-3418.2014.06.010

Meng LH, Zhang XM, Wang H, Dong H, Gu XF, Yu XL, Liu YS. 2019. Yangyin Yiqi Mixture ameliorates bleomycin-induced pulmonary fibrosis in rats through inhibiting TGF-1/smad pathway and epithelial to mesenchymal transition. Evid-Based Complement Alt Med 2019, Article 2710509, 13 pages. https://doi.org/10.1155/2019/2710509

Meng LH, Wang H, Dong H, Gu XF, Yu XL, Liu YS, Xin DY, Qiu XP, Zhang XM. 2019. Intervention mechanism of Yangyin Yiqi heji to alveolus epithel mesenchymal transition in rats with pulmonary fibrosis. J Beijing Univ Trad Chin Med 42: 52 - 57.

Qian J. 2007. Clinical observation of Zhi Ke Ping Chuan decoction in treating 65 cases of childhood asthma. China J Chin Materia Med 32: 1340 - 1342.

Roderfeld M, Graf J, Giese B, Salguero-Palacios R, Tschuschner A, Müller-Newen G, Roeb E. 2007. Latent MMP9 is bound to TIMP-1 before secretion. Biol Chem 388: 1227 - 1234. https://doi.org/10.1515/BC.2007.123

Sibinska Z, Tian X, Korfei M, Kojonazarov B, Kolb JS, Klepetko W, Kosanovic D, Wygrecka M, Ghofrani HA, Weissmann N, Grimminger F, Seeger W, Guenther A, Schermuly RT. 2017. Amplified canonical transforming growth factor- $\beta$ signalling via heat shock protein 90 in pulmonary fibrosis. Eur Respir J 49: 1501941. https://doi.org/10.1183/13993003.01941-2015

Wang H, Li X, Xin DY, Yang XQ. 2016. Effect of Yangyin Yiqi Mixture on quality of life in patients of idiopathic pulmonary fibrosis with deficiency of both qi and yin syndrome. J Trad Chin Med 57: 767 - 770.

Wang JS, Wang H, Wang FS. 2003. Clinical observation of Yangyin Yiqi Mixture in treating 56 patients of SARS recovery period. Beijing J Trad Chin Med 22: 5 - 7.

Xu X, Zhao C, Yang H, Jian Y, Zhang Z, Huang Y. 2011. Anti-inflammatory activity of injectable dexamethasone acetate-loaded nanostructured lipid carriers. Drug Deliv 18: 485 - 492.

https://doi.org/10.3109/10717544.2011.589087

Yan L, Song F, Li H, Li Y, Li J, He QY, Zhang D, Wang F, Zhang M, Zhao H, Feng T, Zhao YY, Wang SW. 2018. 
Submicron emulsion of cinnamaldehyde ameliorates bleomycin-inducedidiopathic pulmonary fibrosis via inhibition of inflammation, oxidative stress and epithelial-mesenchymal transition. Biomed Pharmacother 102: 765 - 771. https://doi.org/10.1016/j.biopha.2018.03.145

Zhang CH, Zhu QJ, Tian JZ. 2017. Progress in evaluation and application of animal models of pulmonary fibrosis induced by bleomycin. Central South Pharm 15: 472 - 475. 